\title{
Collaborating with Young Adults Diagnosed with Schizophrenia: A Participatory Design Study to Shape the Healthcare System
}

\author{
Malene Terp ${ }^{1,2}$, Charlotte D. Bjørnes³, Rikke Jørgensen"1,2, Jan Mainz ${ }^{1,2}$, \\ Birgitte Schantz Laursen 2,3 \\ ${ }^{1}$ Aalborg University Hospital-Psychiatry, Region North Denmark, Aalborg, Denmark \\ ${ }^{2}$ Clinical Institute, Aalborg University, Region North Denmark, Aalborg, Denmark \\ ${ }^{3}$ Clinical Nursing Research Unit, Aalborg University Hospital, Region North Denmark, Aalborg, Denmark \\ Email:m.terp@rn.dk
}

How to cite this paper: Terp, M., Bjørnes, C.D., Jørgensen, R., Mainz, J. and Laursen, B.S. (2017) Collaborating with Young Adults Diagnosed with Schizophrenia: A Participatory Design Study to Shape the Healthcare System. Open Journal of Nursing, 7, 743758.

https://doi.org/10.4236/ojn.2017.77056

Received: June 20, 2017

Accepted: July 16, 2017

Published: July 19, 2017

Copyright $\odot 2017$ by authors and Scientific Research Publishing Inc. This work is licensed under the Creative Commons Attribution International License (CC BY 4.0).

http://creativecommons.org/licenses/by/4.0/

\begin{abstract}
Introduction: Disengagement from mental health services in young adults with schizophrenia has been associated with dissatisfaction and unmet needs. Striving to improve engagement, we invited service users recently diagnosed with schizophrenia to be co-designers of a smartphone technology that will be responsive to their needs. Aim: This paper reports the first phase of a threephased participatory design process. The objective was to identify needs of support in young adults recently diagnosed with schizophrenia and to generate ideas of how the needs could be accommodated using smartphone technology. Methods: Participatory design guided the research process and a qualitative approach was used to generate and analyse the data. Data were generated by means of participant observations ( $n=45$ hours) and interviews ( $n=$ 6) with young adults from a first episode psychosis program in Denmark. Findings: Low levels of knowledge and high levels of uncertainties are characteristic of young adults recently diagnosed with schizophrenia, bringing about a vast need of support in order for them to gain power over their new life situation. Our study suggests that the smartphone may be used to foster empowerment by guiding the young adult's actions in situ, providing comprehensive and easily understood information on the go, allowing for recovery tracking, and notification of mental health changes, providing medication overview and giving easy access to healthcare providers. Conclusion: Young adults recently diagnosed with schizophrenia require comprehensive support in order to become empowered to confidently manage their new life situation. The smartphone holds this potential by offering flexible collaboration and timely access to self-management resources.
\end{abstract}




\section{Keywords}

Empowerment, Mobile Health, Participatory Design, Schizophrenia, Young adults

\section{Introduction}

The early phases of schizophrenia have gained increased attention over the past decade, and today it is well established that when a young adult suffers from a psychotic illness, intensive care is required to control symptoms, prevent psychotic relapse and improve quality of life [1] [2] [3]. Encouraging and promoting service engagement among young adult in the early phases of schizophrenia, however, is a challenge despite intensive and specialized care being routinely offered [4] [5] [6]. This is a serious treat to mental health recovery, as disengagement, when a service is still needed, can lead to devastating consequences [7], including exacerbations of psychotic symptoms [8] [9] social isolation and suicidal behaviour [3].

It is hypothesized that the first five years of schizophrenia care is optimal to change the long-term course of the illness [3]. Fostering service engagement in the early phases of schizophrenia therefore is of particular importance to improve the mental health recovery.

Research has been established that disengagement from mental health services is associated with dissatisfaction [5] and unmet needs [6] in persons with schizophrenia. This provides a strong basis for shaping services around input from service users, which would then foster mental health recovery through healthcare that they themselves perceive to be meaningful and relevant.

Shaping services with mental health users, however, is not common practice [10]. This is true regardless of user-involvement being at the heart of the recommendations for a more modern and sustainable mental healthcare system [10] [11] [12] [13] [14], and irrespective of research designating that service user involvement offers a promising pathway towards better quality healthcare, more efficient care and improved population health [15] [16] [17].

As a result, we set out to shape an early intervention service in collaboration with young adults recently diagnosed with schizophrenia. We wanted to design a service that was "engaging", by grounding the innovation in user needs and by drawing on the power of smartphone technology to extend services beyond the confines of the physical clinic [18] [19] [20]. Smartphone ownership is particularly high in younger people with schizophrenia [21] making the smartphone highly relevant as a tool to respond to service user needs at all times.

This article reports the first phase of a three-phased participatory design process. The objective of the first phase was to identify the needs of support in young adults recently diagnosed with schizophrenia, and to generate ideas of how the needs could be accommodated using smartphone technology. The objective of phase two and three were to design and develop the technology and to 
test it in a clinical setting, respectively.

Figure 1 provides an overview of the different phases and activities in the participatory process of shaping, designing and testing a service with young adults recently diagnosed with schizophrenia.

\section{Methods}

\subsection{Research Design}

The overall research was conducted within a methodological framework of participatory design (PD) [22]. PD has roots in action research [23], and is preoccupied with finding and developing solutions to practical problems in close collaboration with service users [24] [25] [26] [27]. Therefore, PD supports the practice of making service users co-designers of services responsive to their needs.

A qualitative approach was used to generate and analyse the data. In the first phase of the PD process, data were collected through participant observations and interviews with service users from a specialized first episode psychosis program in Denmark (OPUS). OPUS is a two-year program that provides intensive care for young adults between the ages of 18 - 34 years old, recently diagnosed with schizophrenia. Participant observations were carried out to generate a contextual understanding of the young adults' problems and needs, in order to get a grasp of what mattered most to them. Observations were primarily used to identify themes for a semi structured interview guide [28], thus, the findings in this article solely focus on the interviews.

\subsection{Participants and Data Collection}

Firstly, the first author carried out passive participant observations (45 hours) to construct the interview guide. The observations were obtained in the primary contexts of the OPUS program. This included an outpatient clinic in which home consultations were provided as well as an in-patient clinic for young adults only. Observations and field notes were taken concurrently in accordance with Spradleys recommendations [29]. Nine observations of home visits, with two nurses and an occupational therapist, were obtained. The rest of the time was spent in the car or the clinic talking to healthcare professionals (HCPs) about the problems of living with schizophrenia and the needs to be accommo-

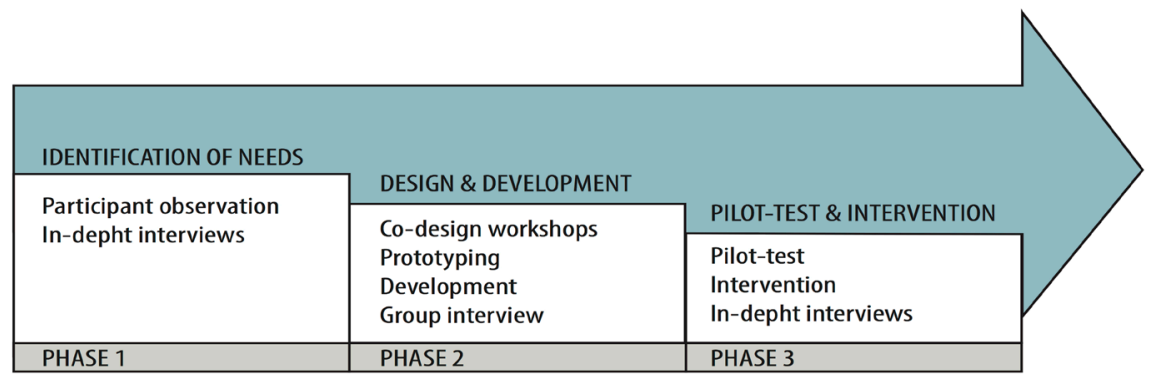

Figure 1. An overview of the different phases and activities in the participatory design process. 
dated. The managers of both settings gave their consent to be observed, and patients were asked permission for the first-author to sit in on conversations between them and their HCP.

Secondly, the first author conducted individual interviews with $(n=6)$ young adults from the OPUS program, using the interview guide. In order to encourage the participants to speak freely, interview questions were open ended and not established in a fixed sequence, rather as prompts [30]. A Venn diagram [31] was used as a tangible artefact to address the supportive network, in an attempt to get an idea of how the technology should be "wired" to accommodate the needs of the young adults in a real life setting. To secure depth of data, each interview was continued until saturation had been reached [32], therefore, the interviews stopped when the narrative became repetitive and no new data were revealed. Interviews lasted between 55 minutes to 1 hour and 18 minutes. They were conducted either at the participants' home (5 interviews) or at the research unit at the hospital (1 interview) depending on participant's preference. Interviews were digitally recorded and transcribed verbatim. The interviews were conducted in Danish; therefore the quotes in the findings section were translated into English, omitting any corrections in phrasing.

Criteria for inclusion in the study were willingness and ability to share information and ideas by virtue of knowledge and experience. However, since it has been argued that individuals who are not "stuck" with too much experience make excellent innovators [33] [34], we were interested in recruiting participants that had been diagnosed within the past year. Criteria for exclusion were inability to speak or understand Danish and unwillingness to provide written consent. Recruitment was conducted in close collaboration with HCPs from OPUS, who singled out relevant participants, gave them an information letter and asked them to consider participation. The first-author contacted them either by phone or email, to make further arrangements, when consent had been obtained.

\subsection{Data Analysis}

A hermeneutical approach to data analysis was chosen. Within this frame of reference, interpretation of meaning is an iterative and circular process [35], which fits the methodology of PD [36]. In the tradition of Gadamer it is rejected, that hermeneutics is a step-by-step method, rather it is an explication of general principles [28]. Guided by canon principles of hermeneutical interpretation, interpretation of meaning was constructed through an incessant back-and forth process between parts and the whole of the interview text, which follows from the hermeneutical circle. The process of hermeneutical questioning continued until an inner unity of a text free of logical contradictions had been reached.

\subsection{Ethical Considerations}

The study was submitted to the North Denmark Region Committee on Health Research Ethics. In accordance with Danish law, the committee found that a formal ethics approval of the study was not required. In line with the Helsinki 
Declaration [37], all participants were fully informed about the purpose of the study and informed consent was obtained both verbally and in writing before enrolment. The participants retained the right to withdraw from the study at any given point, and they were carefully informed, that withdrawal would not influence their course of care. Authorization by the Danish Data Protection Agency was obtained (2008-58-0028).

\section{Findings}

Six participants in the OPUS program were eligible for interviews (four women, two men). All accepted the invitation to participate. At inclusion, the age of the participants ranged between $19-27$ years. All had been diagnosed within the past year, received social benefits and lived independently. All owned a mobile phone and used it on a daily basis.

The hermeneutical inspired process of analysis governing the findings is outlined in Figure 2. Based on the young adults descriptions of living with schizophrenia, we identified a need of support to gain power, to be able to control the new life-situation confidently. The need was related to low levels of knowledge and high levels of uncertainties, making the new and changed life situation somewhat impossible to cope with independently. Six ideas for resources to accommodate the need using smartphone technology were identified. The findings are outlined in the next section.

\begin{tabular}{|c|c|c|c|c|}
\hline $\begin{array}{l}\text { Interview text } \\
\text { Quotations }\end{array}$ & $\begin{array}{l}\text { Immediate answers: What is } \\
\text { said in relation to needs? }\end{array}$ & $\begin{array}{l}\text { De-contextualisation } \\
\text { through interpretation }\end{array}$ & $\begin{array}{l}\text { Result: Needs of support arise } \\
\text { from the coding process }\end{array}$ & $\begin{array}{l}\text { Ideas to accommodate the } \\
\text { needs of support }\end{array}$ \\
\hline $\begin{array}{l}\text { "...would be really nice to get suggestions } \\
\text { for how to help myself [...] and to have the } \\
\text { suggestions handy" }\end{array}$ & $\begin{array}{l}\text { Suggestions for how to help } \\
\text { myself } \\
\text { Have the suggestions handy }\end{array}$ & $\begin{array}{l}\text { Request for power to self- } \\
\text { manage illness on side }\end{array}$ & Support to take actions in-situ & In-situ guidance \\
\hline $\begin{array}{l}\text { "I often forget, how I was yesterday [...] it } \\
\text { feels as though the good days calmly } \\
\text { passes by" }\end{array}$ & $\begin{array}{l}\text { Often forget } \\
\text { Good days passes by }\end{array}$ & $\begin{array}{l}\text { Impaired memory makes } \\
\text { progress hard to recall }\end{array}$ & $\begin{array}{l}\text { Support to recall own process } \\
\text { of recovery }\end{array}$ & Recovery tracking \\
\hline $\begin{array}{l}\text { "Often I do not understand what is going } \\
\text { on [...] really stressful not knowing what } \\
\text { to expect from the illness" }\end{array}$ & $\begin{array}{l}\text { Do not understand } \\
\text { Stressful not knowing what } \\
\text { to expect }\end{array}$ & $\begin{array}{l}\text { Powerless in 'reading' the } \\
\text { illness }\end{array}$ & $\begin{array}{l}\text { Support to identify } \\
\text { deterioration }\end{array}$ & $\begin{array}{l}\text { Notifications of illness } \\
\text { exacerbation }\end{array}$ \\
\hline $\begin{array}{l}\text { "Its really difficult to remember all the } \\
\text { different drugs I have tried the past } \\
\text { year [...] a whole lot easier if I had some } \\
\text { sort of chart at hand that I could show } \\
\text { them" }\end{array}$ & $\begin{array}{l}\text { Difficult to remember } \\
\text { Easier if I had some sort of } \\
\text { chart at hand that I could } \\
\text { show them }\end{array}$ & $\begin{array}{l}\text { Request for help to keep } \\
\text { overview of medication }\end{array}$ & $\begin{array}{l}\text { Support to recall past and } \\
\text { present drugs at all times }\end{array}$ & Wired list of medication \\
\hline $\begin{array}{l}\text { "I searched the Internet for facts about the } \\
\text { illness, just to know what I should expect" }\end{array}$ & $\begin{array}{l}\text { Search the Internet for facts } \\
\text { What I should expect }\end{array}$ & $\begin{array}{l}\text { Internet as source to get } \\
\text { timely information }\end{array}$ & $\begin{array}{l}\text { Comprehensive info around the } \\
\text { clock }\end{array}$ & On demand information \\
\hline $\begin{array}{l}\text { "I'm so happy that she [the nurse] has a } \\
\text { mobile phone. She is always within reach. } \\
\text { That is really comforting to know" }\end{array}$ & $\begin{array}{l}\text { Mobile phone } \\
\text { Always within reach } \\
\text { Comforting }\end{array}$ & $\begin{array}{l}\text { Availability increase sense } \\
\text { of certainty }\end{array}$ & $\begin{array}{l}\text { Boundless and 'out of hours' } \\
\text { communication with health } \\
\text { care providers }\end{array}$ & Online lifeline \\
\hline
\end{tabular}

Figure 2. Outline of the hermeneutical process of analysis governing the study findings. 


\subsection{A Need of Support to Gain Power in Order to Control the New Life Situation Confidently}

\subsubsection{In-Situ Guidance}

The participants emphasized how they sometimes felt powerless and helpless in managing the illness and their new life situation. All had received psychoeducation, either only individually or individually followed by 10 weeks of group sessions with other service users in the OPUS program. The participants were explicit that education about the nature of the illness, recovery rates, medication, relapse prevention and symptom management was truly helpful, and key to becoming in charge of the illness, rather than a victim of it:

"What has helped me the most has been to learn about the illness. When I began to know the signs [of illness] and know when I was extra vulnerable, I got power. Then I was smarter than my own head. There could be just as many questions and concerns, but because I had seen through it [illness], then I could do something in advance-I could act instead of just being a victim."

However, despite their contentment with the psychoeducation, in specific situations they felt incapable of translating the knowledge obtained in the "classroom" into action. Lack of "translation" and "adoption" skills made them reliant on help from their HCPs. Nevertheless, dependency was something the participants strived to extricate themselves from, and they stressed the need of having access to resources, that could guide them "in situ" to self-manage the illness appropriately and pro-actively:

"It would be really nice to get suggestions for how to help myself... and to have the suggestions handy. Then it would be a whole lot easier to manage this in the long run."

Thus, it appeared that extending psychoeducation outside the physical walls of the classroom was crucial for making the young adults more independent and increasing their confidence in their ability to navigate their new life situation. This became especially visible in regard to the time restriction of the OPUS program. Since the program was within a two-year timescale, they were under the pressure of time, learning what to do and how to act unassisted. As such, in-situ guidance emerged as a resource to assist young adults on the go in the process of managing the illness more independently over the course of time.

\subsubsection{Recovery Tracking}

The participants stressed how cognitive impairments were a central feature of their illness. In particular, they emphasised how severe impairment of memory and attention made it hard to recall their own progress, which vastly impacted the hope of recovery. Since experiences were no longer stored in the memory, the good days often faded or even disappeared:

"I often forget, how I was yesterday. It's difficult to remember, what I have been doing, and whether it was a good day or a bad day. It feels as if the good days calmly passes day by day."

The pass of the good days was evident among the participants even though they stressed how the OPUS program had bettered their mental state signifi- 
cantly. Particular on "the bad days", the loss of memory impacted the hope of recovery, as it was difficult to believe that things would actually change for the better:

"Will this ever be better? On the bad days, I really doubt it."

Thus, impaired memory left the participants in doubt of recovery, and maintained a strong presence of the bad days in the memory.

Several of the participants explained how their HCPs had encouraged them to monitor their health in an attempt to call to mind their own progress. Some had taken the word of advice using a diary to record the day; others had discovered that using the camera in their smartphone was a useful strategy to keep a sense of perspective, therefore keeping track of their progress over time. Yet others did not monitor their progress and had discovered how the "bad days" had the strongest presence in their memory.

A participant proposed that systematic tracking of the mental state could help to recall and tell apart the good days and bad days respectively, and emphasised how a display would be an important resource for believing in progress:

"I think that getting things in black and white could help to convince me that I am getting better."

As such, it appeared that recovery tracking could help provide a more accurate and realistic picture of the process of recovery, particularly if the tracking were presented visually. Thus, recovery tracking emerged as an important feature to keep up the hope of recovery and to escape the mental captivity of illness.

\subsubsection{Notifications of Illness Exacerbation}

Fear of illness exacerbation was widely recognized by the participants. They emphasised how the OPUS program had improved their mental state significantly, yet, still they persistently wondered whether and when the illness would "strike" again. They were highly alert of early warning signs of impending psychotic relapse, as were their relatives. In fact, their mind was almost programmed to think that even small changes in the mental state could be deterioration:

"What is this... a relapse? Honestly, that is always the first thing I think of. The thought of relapse and hospitalization really freaks me out."

The thoughts of relapse and hospitalization were dominant, and it appeared that the participants had difficulty "reading" the illness. Since they did not know what to pay attention to and what to let pass unattended, they identified all information from the senses as potential signs of impending psychotic relapse:

"Is it the illness speaking now, or is it just me being young?"

As such, lack of knowledge and insight into their relapse signature and drill left them in an incessant potential danger, not knowing for certain whether to be worried or not. The uncertainty was evident over the course of time. A participant explained how, still after one year in the OPUS program, he found it difficult to interpret fatigue, for example. This could be interpreted as a negative symptom (something normal for people suffering from schizophrenia), an early sign of illness exacerbation (a potential danger that should be acted upon) but 
also, a healthy reaction to living an irregular and "normal" youth life, occasionally having too little sleep.

The sustained problem of reading the illness prevented the participants from knowing whether to be worried or not, thus preventing them from "becoming the captain of one's own life" as one of the participants framed it. This restricted their ability to be proactive. Further, this left them watchful 24/7-worried and controlled by their illness, rather than certain and in control of it:

"Sometimes it feels as if $\mathrm{P} m$ at work nonstop. It would be so helpful, if I could get some kind of warning telling me when to be alert. Then I could focus less on my illness and more on just living my life."

Thus, notifications of illness exacerbation appeared to be a resource of paramount importance to promote a sense of confidence and control in their life with their illness, but also in "taking time off" from the illness, and focusing on being young rather than being ill.

\subsubsection{Wired List of Medications}

The participants stressed how the severe impairment of memory and attention, did not only impact their hope of recovery, but also their ability to keep track of their medications. Most stressed how they had control of taking their daily medication through different routines, but found it difficult to remember the names, types and doses of different psychotropic drugs, particularly ones used in the past. This left them powerless, particularly in stressful situations, where they had to account for it:

"It's really difficult to remember all the different drugs I have tried the past year. If they ask me at the General practitioner or the Emergency room, I can't really report it, to be quite honest."

Having a sense of perspective of prescribed medication, both present and past, was greatly stressed as a means to be in control, and several stressed how a list of wired medications would be a helpful resource to recall this:

"It would be a whole lot easier if I had some sort of list at hand that I could show them."

The emphasis of having a list at hand pointed towards the importance of ubiquity in order to support the memory. Thus, a wired list of medications emerged as an important resource to keep a sense of perspective and feel in control.

\subsubsection{On-Demand Information}

The need for widespread and timely information was evident among the participants. All turned to websites looking for information about the nature of illness, treatment options, rates of recovery, medication, as well as tips and tools to fight and manage the illness and their new life situation. This was particularly true when they had just been diagnosed:

"At first, I really needed information. I searched the Internet for facts about the illness, just to know what I should expect the first couple of months... Because, $F^{* * *}$ they were hard." 
As such, the Internet was used as a tool to seek answers and self-educate. However, the information on the Internet, did not necessarily empower them:

"It [information] can be really hard to understand, but also to relate to, since they use so many trade terms."

Thus, it appeared, that easily comprehensible information was key in order to keep a sense of perspective in the process of preparing for the time to come. As such, the participants pointed towards the importance of an on-demand information resource that was simple and enlightening, thus workable and applicable in the early phases of schizophrenia where the level of knowledge was low and the level of uncertainties high.

A participant shared the idea that the application could provide an encyclopaedia consisting of a knowledgebase with a search option similar to Google, and an interactive part where all the patients enrolled in the OPUS program could share their tips and tools, therefore providing each other with useful information through websites and articles. Thus, the active role in sharing and disseminating meaningful information was mentioned as an important aspect to take into account in the re-design of standard formats of information and learning aids.

\subsubsection{Online Lifeline}

The participants stressed the importance of easy access to their HCP. In this respect, they highlighted how their mobile phone was the platform commonly used to reach out for guidance and directions. This mode of contact was really reassuring:

"P $m$ so happy that she [the HCP] has a mobile phone. She is always within reach. That is really comforting to know."

As such, the mobile phone served as an online lifeline ensuring that qualified advices was within reach regardless of time and place.

Reaching out for guidance and directions appeared to be equally important day and night. In fact, nights were often the time of day where the participants felt the biggest need for help and guidance:

"After dark, I often feel anxious. That is the time of day where I feel most vulnerable."

The OPUS program, however, was only available during office hours. Consequently, it was not possible to communicate with the HCPs after 4 pm. Yet, several of the participants sent texts to the HCPs after hours, knowing that their messages would not be seen or answered until the next day. They had experienced how just getting things off their chest made them calm down and relax:

"It's really nice that you can always write down things and send it off straight away, even in the middle of the night. Then [name of the HCP] can look at it when she has got the time: read through it, analyse it and send it back."

An important feature of the lifeline was customized guidance and directions. To this end, written communication was highly emphasised. The participants explained how their impaired memory and short attention span made it not only hard to focus, but also to remember the verbal advice received by phone. This 
made written guidance somewhat more supportive in controlling their new life situation:

"It is really hard for me to communicate [verbally], since I have to think fast and remember what has been said afterwards. It is much easier and convenient to have things in writing."

As a result, it appeared that the mobile phone served the means of an online lifeline, making help and guidance feel accessible. Yet, the mobile phone emerged as a key feature in establishing a secure and empowering environment that enabled the participants to take time off from the illness, even in their most vulnerable hours where many questions and doubts arose.

Summing up, six ideas for supportive resources of power for the participant's to control their new life situation were identified. The findings are synthesised in Figure 3.

\section{Discussion}

The findings presented here provide new insights into the users' perspectives on the needs of support when being young and recently diagnosed with schizophrenia, including potential features that should be considered in designing a smartphone technology to accommodate these needs. Our study highlights that a smartphone technology should be designed to promote empowerment while responding to the needs required to confidently navigate this new life situation.

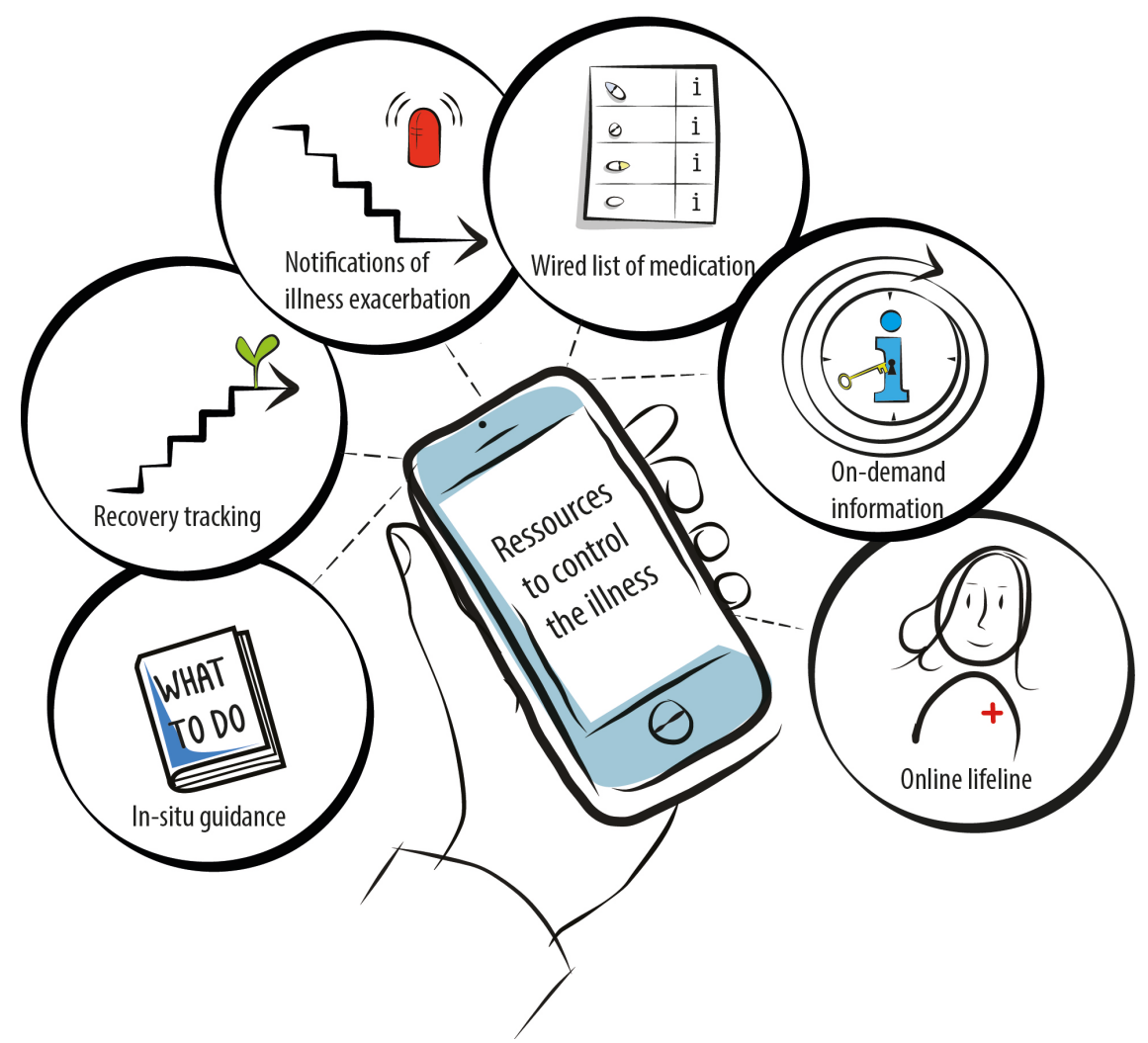

Figure 3. Synthesis of findings. 
There is growing evidence that the perception of personal control plays a critical role in health and wellbeing [38], and finding ways to increase this power is important as a means to this end [39]. We identified six ways to increase this power in the early phases of schizophrenia, where the levels of knowledge are low and uncertainties high.

The analysis revealed that knowledge is a source of power, which is of great importance to control the new life situation independently. In-situ guidance, on-demand information and on-line lifeline were all different means to this end. The power of knowledge is highly recognized in psychoeducation literature [40], where evidence has been established that education helps individuals with schizophrenia gain basic knowledge on their illness [41]. Our study signifies that young adults with schizophrenia want to be educated in order to self-manage their illness, but they are unable to use the knowledge obtained outside the classroom to do this effectively. These findings are concurrent with previous studies claiming that knowledge gained through psychoeducation does not appear to help individuals with schizophrenia to manage their illness better or engage actively in the recovery process [41] [42]. Considered together, this substantiates the relevance of ubiquity to be able to assist young adults on the go, in the process of resuming the management of their lives independently.

The analysis revealed that memory is another important source of power to feel certain and in control of the new life situation. In this respect, recovery tracking and a wired list of medications came up as resources to help memorizing and keeping a sense of perspective. Cognitive impairments are a distinct dimension of schizophrenia and are highly evident in persons with this illness [43], as was widely evident in our sample. Cognitive deficits have emerged as an important new target in schizophrenia care, due to evidence suggesting that they are critically related to difficulties of functioning in everyday life [44]. Our study indicates that the smartphone may play an important role in compensating for cognitive deficits, therefore providing improved functioning in everyday life for those with schizophrenia. More importantly, our findings suggest that memory support may help keep the good days present, when the hope of recovery is hard to obtain. Thus, recovery tracking appears vital to sustain hope in the young adults on their journey towards mental health recovery.

Also, the analysis revealed how warnings are an important source of power to assert control. To this end, notifications of illness exacerbation came up as an idea to provide a sense of certainty and control in managing their new life situation. Birchwood proposes that persons with schizophrenia have a strong interest in learning to recognize and prevent impending psychotic relapse [45], and stresses the importance of promoting a sense of control through knowledge and insight into their relapse signature and drill [46]. This is in line with our findings, which eventually suggests that reading the illness and recognizing early signs of change is somewhat impossible in the early phases of schizophrenia, which makes notification of undesirable changes crucial to assert control. Notifications of illness exacerbations may be provided using smartphone technology. 
The persuasive personal monitoring system, MONARCA, developed for the treatment of persons with bipolar disorder, is an example of this. This system uses an automatic trigger mechanism to detect early changes in the mental state through electronic self-assessments provided by the patients [47].

Summing up, our study advocates that control in the management of the early phases of schizophrenia may be achieved if support is extended into the everyday lives and homes of the young adults, where powerlessness, helplessness and worries develop. The smartphone, which enables digital engagement with patients in real time and real environments [48], may facilitate this process through easy and timely access to support. Firth and Torous [49] have documented high rates of engagement and satisfaction with apps in the care of people with schizophrenia. This further encourages the nascent potential of the mode of service delivery to accommodate the needs of young adults with schizophrenia at all times.

\section{Study Limitations}

The study was conducted with rigorous qualitative methodology, but there are some limitations.

The majority of the sample population were women. Since first episode schizophrenia incident rates are approximately two times higher in males than women [21] [50] our sample is gender biased. This might indicate that our findings are in favour of women, however, we did not see any distinct differences in relation to the needs of support in the two genders.

The sample was small and the study only included ethnic Danes from one outpatient clinic. Thereby, it reflects the culture, norms and values of young ethnic Danes, in a specific clinic at a specific time. It might be argued that a variation in ethnicity might have broadened the perspective of needs and ideas for their accommodation, particular since needs may vary over the course of an illness and depend on a patient's health status, demographics and culture [39]. This could affect the transferability of our results. Thus, it would be interesting to replicate the study in other contexts, countries and within different ethnic groups.

There were no distinct differences in experiences and statements from the participants; thus, the sample size appears to be adequate for the subject studied. However, the cognitive difficulties addressed in the findings, and widely documented in the literature [43], questions whether data saturation was actually reached. Even though the interviewer experienced saturation during each interview, there is a risk that some complexities did not unfold.

\section{Conclusion}

This study demonstrates that young adults with first episode schizophrenia need comprehensive support to become empowered to manage and feel certain in their new and changed life situation. Our study suggests that the smartphone may be used to foster empowerment by guiding the young adult's actions in situ, 
providing comprehensive and easily understood information on the go, allowing for recovery tracking, and notification of mental health changes, providing medication overview and giving easy access to HCPs. The high rates of engagement and satisfaction with apps in the care of people with schizophrenia encourage the nascent potential of the mode of smartphone service delivery to accommodate the needs of support at all times.

\section{Clinical Implications}

Our study advocates that smartphone technology holds the promise of empowering young adults newly diagnosed with schizophrenia to manage their new life situation confidently through easy and timely access to flexible collaboration and self-management resources. One thing to be aware of, however is, that patient empowerment may lead to over-involvement in own care [39]. Generally, over-involvement has gained less attention than under-involvement, although evidence has been provided that both types of mismatches affect patient satisfaction [51]. Since dissatisfaction is associated with disengagement from mental health services in young adults with schizophrenia [5], it appears crucial that HCPs continually assess with the patient whether the technology has become a burden. Otherwise, the technology may foster service disengagement rather than encourage and promote engagement. This strongly indicates the need for further research on the topic, and highlights that future studies could benefit from not exclusively addressing how the smartphone may promote empowerment, but also when and how such a technology may defeat its own purpose.

\section{Acknowledgements}

This study was funded by a grant from the Tryg Foundation and the Lundbeck Foundation, Denmark. We want to express our gratitude to the funding source, which had no involvement in the study. Also, we want to express our heartfelt thanks to the young adults who took their time to participate in the study, including consultant and service user Camilla Krogh, who helped us to synthesize our findings into a drawing. Without the commitment of the young adults this study would never have become a reality. Last but not least, we want to thank Research Officer, Julie Walsh, Lawson Health Research Institute, for proofreading.

\section{References}

[1] Larsen, J.A. (2007) Understanding a Complex Intervention: Person-Centred Ethnography in Early Psychosis. Journal of Mental Health, 16, 333-345.

https://doi.org/10.1080/09638230701299186

[2] Jorgensen, P., Nordentoft, M., Abel, M.B., Gouliaev, G., Jeppesen, P. and Kassow, P. (2000) Early Detection and Assertive Community Treatment of Young Psychotics: The Opus Study. Rationale and Design of the Trial. Social Psychiatry and Psychiatric Epidemiology, 35, 283-287. https://doi.org/10.1007/s001270050240

[3] Nordentoft, M., Melau, M., Iversen, T., Petersen, L., Jeppesen, P., Thorup, A., Bertelsen, M., Hjorthøj, C.R., Hastrup, L.H. and Jørgensen, P. (2015) From Research to 
Practice: How OPUS Treatment Was Accepted and Implemented throughout Denmark. Early Intervention in Psychiatry, 9, 156-162. https://doi.org/10.1111/eip.12108

[4] Stowkowy, J., Addington, D., Liu, L., Hollowell, B. and Addington, J. (2012) Predictors of Disengagement from Treatment in an Early Psychosis Program. Schizophr Res Elsevier B. V., 136, 7-12.

[5] O’Brien, A., Fahmy, R. and Singh, S.P. (2009) Disengagement from Mental Health Services. A Literature Review. Social Psychiatry and Psychiatric Epidemiology, 44, 558-568. https://doi.org/10.1007/s00127-008-0476-0

[6] Kreyenbuhl, J., Nossel, I.R. and Dixon, L.B. (2009) Disengagement from Mental Health Treatment among Individuals with Schizophrenia and Strategies for Facilitating Connections to Care: A Review of the Literature. Schizophrenia Bulletin, 35, 696-703. https://doi.org/10.1093/schbul/sbp046

[7] Conus, P., Lambert, M., Cotton, S., Bonsack, C., McGorry, P.D. and Schimmelmann, B.G. (2010) Rate and predictors of service disengagement in an epidemiological first-episode psychosis cohort. Schizophr Res Elsevier B. V., 118, 256-263.

[8] Craig, T.K.J. (2004) The Lambeth Early Onset (LEO) Team: Randomised Controlled Trial of the Effectiveness of Specialised Care for Early Psychosis. BMJ, 329, 1067. https://doi.org/10.1136/bmj.38246.594873.7C

[9] Lester, H., Marshall, M., Jones, P., Fowler, D., Amos, T., Khan, N. and Birchwood, M. (2011) Views of Young People in Early Intervention Services for First-Episode Psychosis in England. Psychiatric Services, 62, 882-887.

https://doi.org/10.1176/ps.62.8.pss6208_0882

[10] Ion, R.M., Cowan, S. and Lindsay, R. (2010) Working with People Who Have Been There: The Meaningful Involvement of Mental Health Service Users in Curriculum Design and Delivery. The Journal of Mental Health Training, Education and Practice, 5, 4-11. https://doi.org/10.5042/jmhtep.2010.0214

[11] Millar, S.L., Chambers, M. and Giles, M. (2016) Service User Involvement in Mental Health Care: An Evolutionary Concept Analysis. Health Expectations, 19, 209-221. https://doi.org/10.1111/hex.12353

[12] Crawford, M.J., Rutter, D., Manley, C., Weaver, T., Bhui, K., Fulop, N. and Tyrer, P. (2002) Systematic Review of Involving Patients in the Planning and Development of Health Care. BMJ, 325, 1263. https://doi.org/10.1136/bmj.325.7375.1263

[13] Rutter, D., Manley, C., Weaver, T., Crawford, M.J. and Fulop, N. (2004) Patients or Partners? Case Studies of User Involvement in the Planning and Delivery of Adult Mental Health Services in London. Social Science \& Medicine, 58, 1973-1984.

[14] Omeni, E., Barnes, M., MacDonald, D., Crawford, M. and Rose, D. (2014) Service User Involvement, Impact and Participation: A Survey of Service User and Staff Perspectives. BMC Health Services Research, 14, 491. https://doi.org/10.1186/s12913-014-0491-7

[15] Carman, K.L., Dardess, P., Maurer, M., Sofaer, S., Adams, K., Bechtel, C. and Sweeney, J. (2013) Patient and Family Engagement: A Framework for Understanding the Elements and Developing Interventions and Policies. Health Affairs, 32, 223-231. https://doi.org/10.1377/hlthaff.2012.1133

[16] Coulter, A. (2012) Patient Engagement-What Works? The Journal of Ambulatory Care Management, 35, 80-89. https://doi.org/10.1097/JAC.0b013e318249e0fd

[17] Institute of Medicine (2001) Committee on Quality of Health Care in America. Crossing the Quality Chasm: A New Health System for the 21st Century. National Academy Press, Washington DC. 
[18] Donker, T., Petrie, K., Hons, B., Proudfoot, J., Clarke, J., Birch, M. and Christensen, H. (2013) Smartphones for Smarter Delivery of Mental Health Programs: A Systematic Review. Journal of Medical Internet Research, 15, 1-13. https://doi.org/10.2196/jmir.2791

[19] World Health Organization (2011) mHealth, New Horizons for Health through Mobile Technologies. Observatory, 3, 112.

[20] Hanlon, P.O., Aref-adib, G., Fonseca, A., Lloyd-evans, B., Osborn, D. and Johnson, S. (2016) Tomorrow's World, Current Developments in the Therapeutic Use of Technology for Psychosis. BJPsych Advances, 22, 301-310. https://doi.org/10.1192/apt.bp.115.014654

[21] Lal, S., Dell'Elce, J., Tucci, N., Fuhrer, R., Tamblyn, R. and Malla, A. (2015) Preferences of Young Adults with First-Episode Psychosis for Receiving Specialized Mental Health Services Using Technology: A Survey Study. JMIR Mental Health, 2, e18. https://doi.org/10.2196/mental.4400

[22] Spinuzzi, C. (2005) The Methodology of Participatory Design. Technical Communication, 52, 163-174.

[23] Kensing, F. (2003) Methods and Practices in Participatory Design. ITU Press, Copenhagen.

[24] Clemensen, J., Rothmann, M.J., Smith, A.C., Caffery, L.J. and Danbjorg, D.B. (2016) Participatory Design Methods in Telemedicine Research. Journal of Telemedicine and Telecare, 1-6.

[25] Clemensen, J., Larsen, S.B., Kyng, M. and Kirkevold, M. (2007) Participatory Design in Health Sciences, Using Cooperative Experimental Methods in Developing Health Services and Computer Technology. Qualitative Health Research, 17, 122-130. https://doi.org/10.1177/1049732306293664

[26] Kushniruk, A. and Nøhr, C. (2016) Participatory Design, User Involvement and Health IT Evaluation. Studies in Health Technology and Informatics, 222, 139-151.

[27] Terp, M., Laursen, B.S., Jørgensen, R., Mainz, J. and Bjørnes, C.D. (2016) A Room for Design, through Participatory Design Young Adults with Schizophrenia Become Strong Collaborators. International Journal of Mental Health Nursing, 25.

[28] Kvale, S. and Brinkmann, S. (2009) InterViews, Learning the Craft of Qualitative Research Interviewing. Sage Publications, Los Angeles.

[29] Spradley, J. (1980) Participant Observation. Holt Rinehart and Winston, New York.

[30] Hammersley, M. (2010) Ethnography, Principles in Practice. 3rd Edition, Routledge, London, New York.

[31] Kanstrup, A.M. and Bertelsen, P. (2011) User Innovation Management: A Handbook. Aalborg Denmark, Aalborg University Press.

[32] O’Reilly, M. and Parker, N. (2012) “Unsatisfactory Saturation”: A Critical Exploration of the Notion of Saturated Sample Sizes in Qualitative Research. Qualitative Research, 13, 190-197. https://doi.org/10.1177/1468794112446106

[33] Kanstrup, A.M. and Christiansen, E. (2006) Selecting and Evoking Innovators, Combining Democracy and Creativity. Proceedings of the 4 th Nordic Conference on Human-Computer Interaction, 321-330. https://doi.org/10.1145/1182475.1182509

[34] Thomke, S. and von Hippel, E. (2002) Customers as Innovators: A New Way to Create Value. Harvard Business Review, 74-81.

[35] Gadamer, H.-G. (2013) Truth and Method. Revised 2nd Edition, Bloomsbury Academic, London. 
[36] Bjørnes, C.D. (2011) The Patients' Health Informatics Tool-Exploring the Possibilities: A Web 2.0 Application for Men with Prostate Cancer. Virtual Centre for Health Informatics, Aalborg University, Aalborg.

[37] WMA (2013) WMA Declaration of Helsinki-Ethical Principles for Medical Research Involving Human Subjects.

[38] Rodin, J. (1986) Aging and Health, Effects of the Sense of Control. Science, 233, 1271-1276. https://doi.org/10.1126/science.3749877

[39] Angelmar, R. and Berman, P.C. (2007) Patient Empowerment and Efficient Health Outcomes. In: Financing Sustainable Healthcare in Europe, New Approaches for New Outcomes, Conclusions from a Collaborative Investigation into Contentious Areas of Healthcare, Grand Duchy of Luxembourg, Ministry of Health, Luxembourg, 139-162.

[40] Xia, J., Merinder, L.B. and Belgamwar, M.R. (2014) Europe PMC Funders Group Psychoeducation for Schizophrenia. Psychiatry and Clinical Neurosciences, 1-157.

[41] Vreeland, B., Minsky, S., Yanos, P.T., Menza, M., Gara, M., Kim, E., Toto, A.M. and Allen, L. (2006) Efficacy of the Team Solutions Program for Educating Patients about Illness Management and Treatment. Psychiatric Services, 57, 822-828. https://doi.org/10.1176/ps.2006.57.6.822

[42] Mueser, K.T. and Mcgurk, S.R. (2004) Schizophrenia. The Lancet, 363, 2063-2072.

[43] Harvey, P.D. (2013) Cognitive Aspects of Schizophrenia. Wiley Interdisciplinary Reviews. Cognitive Science, 4, 599-608. https://doi.org/10.1002/wcs.1253

[44] Gold, J.M. (2004) Cognitive Deficits as Treatment Targets in Schizophrenia. Schizophrenia Research, 72, 21-28.

[45] Birchwood, M. (2000) Schizophrenia, Early Warning Signs. Advances in Psychiatric Treatment, 6, 93-101. https://doi.org/10.1192/apt.6.2.93

[46] Birchwood, M. and Spencer, E. (2001) Early Intervention in Psychotic Relapse. Clinical Psychology Review, 21, 1211-1226.

[47] Frost, M., Marcu, G., Hansen, R., Szaántó, K. and Bardram, J. (2011) The Monarca Self-Assessment System, Persuasive Personal Monitoring for Bipolar Patients. Proc 5 th Int ICST Conf Pervasive Comput Technol Healthc Ieee. https://doi.org/10.4108/icst.pervasivehealth.2011.246050

[48] Ben-Zeev, D. (2017) Technology in Mental Health, Creating New Knowledge and Inventing the Future of Services. Psychiatric Services, 68, 107-108. https://doi.org/10.1176/appi.ps.201600520

[49] Firth, J. and Torous, J. (2015) Smartphone Apps for Schizophrenia: A Systematic Review. JMIR mHealth uHealth, 3, e102. https://doi.org/10.2196/mhealth.4930

[50] Amminger, G., Harris, M., Conus, P., Lambert, M., Elkins, K., Yuen, H.-P. and McGorry, P. (2006) Treated Incidence of First-Episode Psychosis in the Catchment Area of EPPIC between 1997 and 2000. Acta Psychiatrica Scandinavica, 114, 337345. https://doi.org/10.1111/j.1600-0447.2006.00790.x

[51] Lantz, P.M., Janz, N.K., Fagerlin, A., Schwartz, K., Liu, L., Lakhani, I., Salem, B. and Katz. S.J. (2005) Satisfaction with Surgery Outcomes and the Decision Process in a Population-Based Sample of Women with Breast Cancer. Health Services Research, 40, 745-767. https://doi.org/10.1111/j.1475-6773.2005.00383.x 
Submit or recommend next manuscript to SCIRP and we will provide best service for you:

Accepting pre-submission inquiries through Email, Facebook, LinkedIn, Twitter, etc. A wide selection of journals (inclusive of 9 subjects, more than 200 journals)

Providing 24-hour high-quality service

User-friendly online submission system

Fair and swift peer-review system

Efficient typesetting and proofreading procedure

Display of the result of downloads and visits, as well as the number of cited articles Maximum dissemination of your research work

Submit your manuscript at: http://papersubmission.scirp.org/

Or contact ojn@scirp.org 